\title{
Consolidation effect of dredged soil by siphon method focusing on the porous filter material
}

\author{
Ryohei Ishikura ${ }^{\text {i) }}$, Shodai Soda ${ }^{\text {ii) }}$ and Shintaro Miyamoto ${ }^{\text {iii) }}$
}

\begin{abstract}
i) Assistant Professor, Department of Civil Engineering, Kyushu University, 744, Motooka, Nishi-ku,Fukuoka 819-0395, Japan.
ii) Graduate Student, Department of Civil Engineering, Kyushu University, 744, Motooka, Nishi-ku,Fukuoka 819-0395, Japan.

iii) Ph.D Student, Department of Civil Engineering, Kyushu University, 744, Motooka, Nishi-ku,Fukuoka 819-0395, Japan.
\end{abstract}

\begin{abstract}
The disposal of the dredged soil has recently become a worldwide problem. In order to utilize high water content soil material, it is essential to dewater and increase the soil strength. There are urgent demands for developing an alternative new method to dewater the dredged soils in more economical and environment-friendly viewpoint. In this paper, siphon method with porous filter material is proposed to dewater the high water content dredged soil. In order to clarify the availability and effectiveness of this method, a series of tests were performed to investigate the dewatering behavior and strength of the dredged soil with vacuum and siphon methods. It was found that there is some possibility to dewater the dredged soil by using siphon method with vertical pressure.
\end{abstract}

Keywords: consolidation, siphon method, dewatering, granular blast furnace slag

\section{INTRODUCTION}

Recently, the disposal of the dredged soil has become a worldwide problem. In order to utilize high water content soil material, it is essential to dewater and increase the soil strength. There are urgent demands for developing an alternative new method to dewater the dredged soils in more economical and environment friendly viewpoint without using electricity instead of the conventional techniques such as vacuum consolidation method.

In order to utilize the dredged soil as high strength material, high-strengthening of cement treated clay by mechanical dehydration was developed (Kasama et al., 2007). On the other hand, in order to purify the water including pollutants, porous materials such as natural zeolite are recently used as the countermeasure against water quality purification (Umezaki et al., 2011). In addition, utilization of porous materials such as granular blast furnace slag (GBF-slag) that has latent hydraulic properties to the soil structures is also investigated (Matsuda et al., 2012).

Fig.1 shows the schematic illustration of embankment construction that possess the drainage and purification function by utilizing clean energy such as siphon method. As shown in this figure, by using adsorption effect of porous material such as zeolite, GBF-slag, there is some possibility to dewater the dredged soil and to establish purification technology of contaminated soil by the drainage water passing through the porous filter materials.

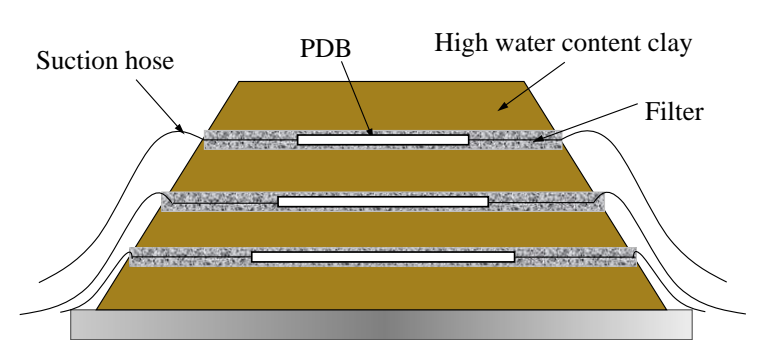

Fig.1. Schematic illustration of embankment construction.

In this study, porous materials and a general particle material (Tong et al.,2010) were used as the filter materials for investigating the dewatering and adsorption effect. Siphon method is proposed to dewater the high water content dredged soil with horizontally installed plastic board drain and filter material. The availability and effectiveness of this method were discussed.

\section{CONSOLIDATION TEST BY SIPHON}

\subsection{Dredged soil and filter materials}

The dredged soil as a representative of high water content clay, which was sampled in Kanmon route was used in this study. The dredged soil that has passed through $2 \mathrm{~mm}$ sieve was tested in this experiment. Table1 shows the summary of properties for dredged soil. GBF-slag and zeolite were chosen as porous materials which the pollutant adsorption effect could be expected for the filter material. GBF-slag which is by-product generated during manufacturing process of iron and has processed the latent hydraulic properties to 
Table1. Summary of properties for dredged soil.

\begin{tabular}{c|c|c}
\hline $\begin{array}{c}\text { Soil particle density } \\
\rho_{\mathrm{S}}\left(\mathrm{g} / \mathrm{cm}^{3}\right)\end{array}$ & $\begin{array}{c}\text { Liquid limit } \\
w_{\mathrm{L}}(\%)\end{array}$ & $\begin{array}{c}\text { Plastic limit } \\
w_{\mathrm{P}}(\%)\end{array}$ \\
\hline 2.697 & 95.0 & 35.91 \\
\hline $\begin{array}{c}\text { Initial water content } \\
w_{\text {ini }}(\%)\end{array}$ & $\begin{array}{c}\text { Initial void ratio } \\
e_{\text {ini }}\end{array}$ & $\begin{array}{c}\text { Compression index } \\
C_{c}\end{array}$ \\
\hline 168.20 & 4.28 & 0.44 \\
\hline
\end{tabular}

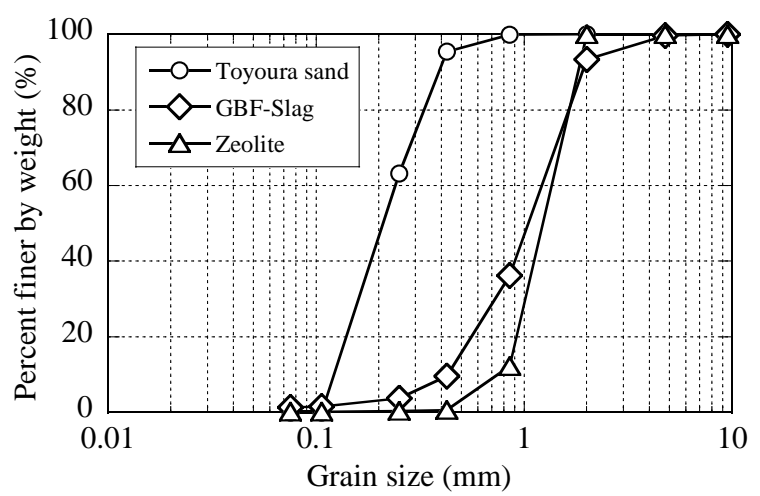

Fig.2. Particle size distribution curves of filter materials.

solidify in response to water with time Toyoura sand was also used as non porous material for the filter material. The particle size distribution curves of filter materials are shown in Fig.2.

\subsection{Test method and procedure}

The experiment container which is approximately $49 \mathrm{~cm}$ inside diameter in Fig.3 was used in this study. Plastic Board Drain (PBD) which connected a tube was located at the bottom of the container. The filter material is compacted at $90 \%$ of degree of compaction around $5 \mathrm{~cm}$ in height, and later, water is poured into the filter material from the bottom of the container for increasing the filter saturation. Dredged soil was adjusted at in-site initial water content state $\left(w_{\text {ini }}=170 \%\right)$, then was poured into the container to a height of $15 \mathrm{~cm}$ with degassing. Consolidation drainage tests were performed by acting the negative pressure of siphon water head difference about $42.5 \mathrm{kPa}(4.25 \mathrm{~m})$. The experiments in the same negative pressure conditions using the vacuum pump were also performed.

\subsection{Test results and discussions}

In order to confirm the drainage performance of the filter materials, the relationships between drainage amount and elapsed time were investigated as shown in Fig.4. The case of $20 \mathrm{~cm}$ water depth without filter material was compared with the cases of $15 \mathrm{~cm}$ water depth with $5 \mathrm{~cm}$ height of filter materials. As shown in this figure, it was found that types of filter had little influence on the drainage amounts. It was also confirmed that the diameter of tube had no influence on the drainage amounts. Fig.5 shows the relationships between drainage amounts and elapsed time by using

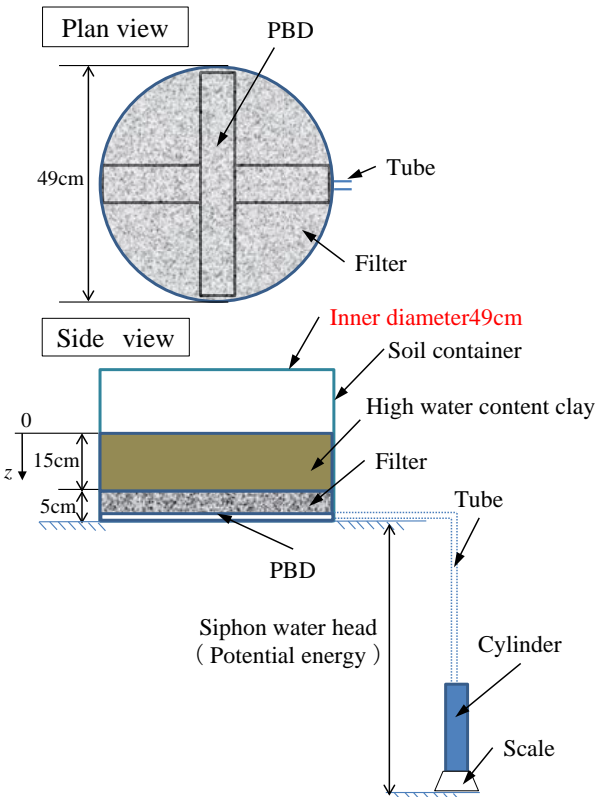

Fig.3.Consolidation test apparatus by siphon method.

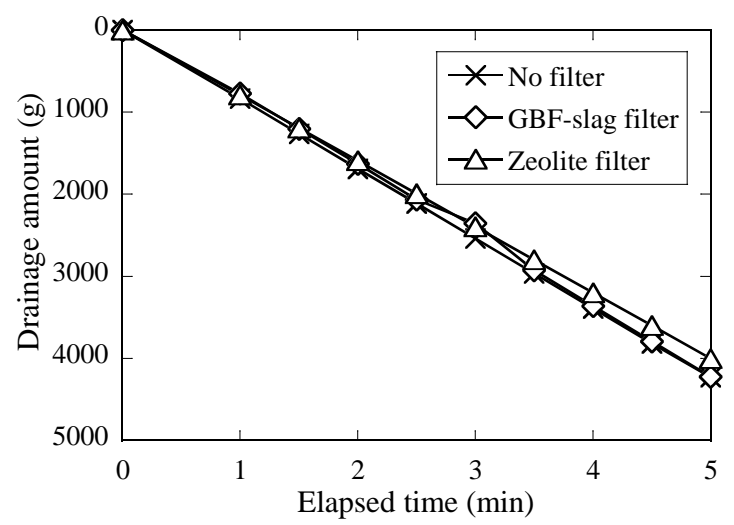

Fig.4. Drainage performance of the filter materials.

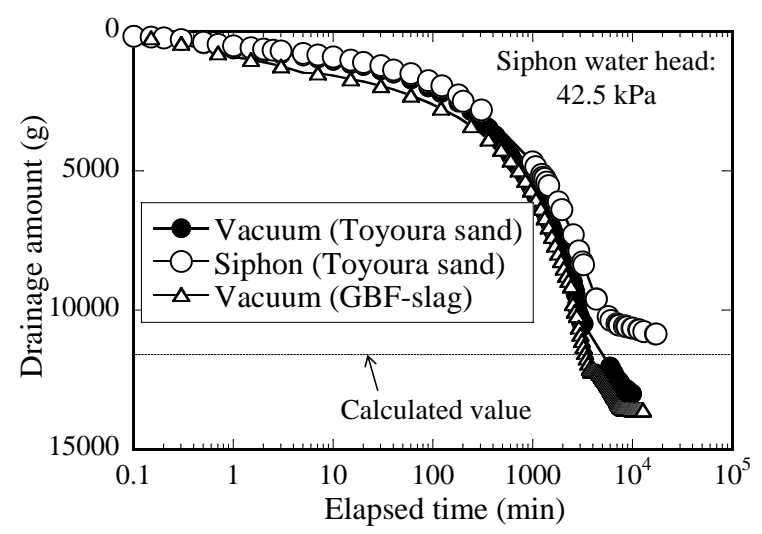

Fig.5. The relationships between drainage amount with time of Toyoura sand.

siphon and vacuum method. As shown in this figure, it was found that the consolidation drainage amount and elapsed time relationship curve using the principle of siphon is similar to that of the vacuum pump until around 24 hours, however, after around 24 hours, this relationship curve using siphon method had different tendency in comparison with that of the vacuum pump 


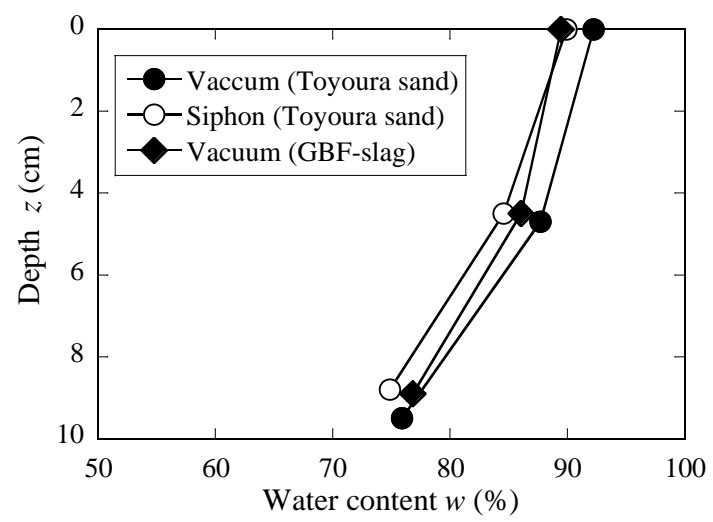

Fig.6. Water content distributions to the depth.

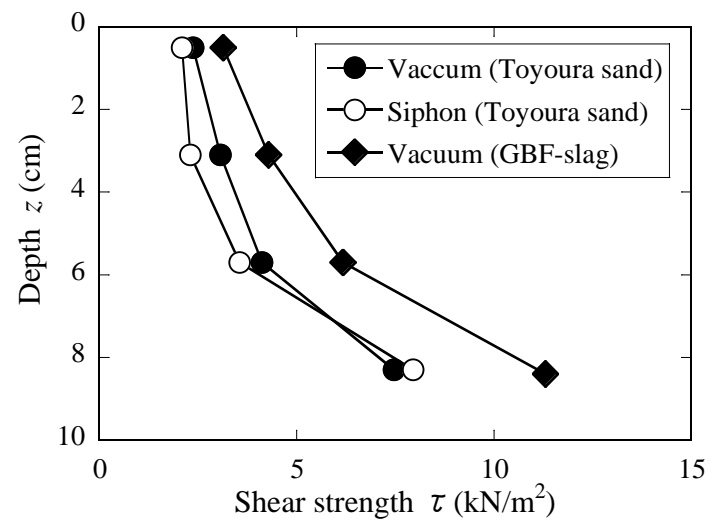

Fig.7. Shear strength distributions to the depth.

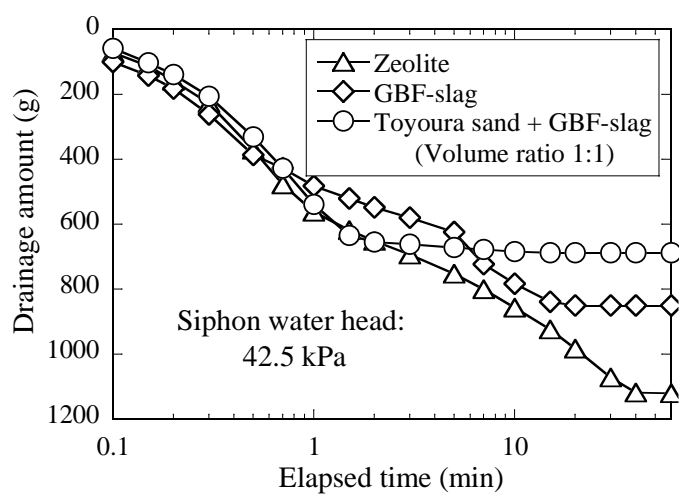

Fig.8. The relationships between drainage amount with time of porous filter materials.

in the case of using Toyoura sand filter. This figure had also shown that kinds of filter material(Toyoura sand and GBF-slag) had little influence on the relationships between drainage amount and elapsed time by using vacuum method. After consolidation finished, water content and shear strength by vane shear test were investigated at each depth. The plots were the averaged values of six points.

Fig.6 shows the relationships between water content and depth after consolidation. The results by the vacuum pump using GBF-slag as a filter material were plotted in this figure. The water content decreased with an increase of depth, which is closer to the filter material. Types of filter materials and dewatering

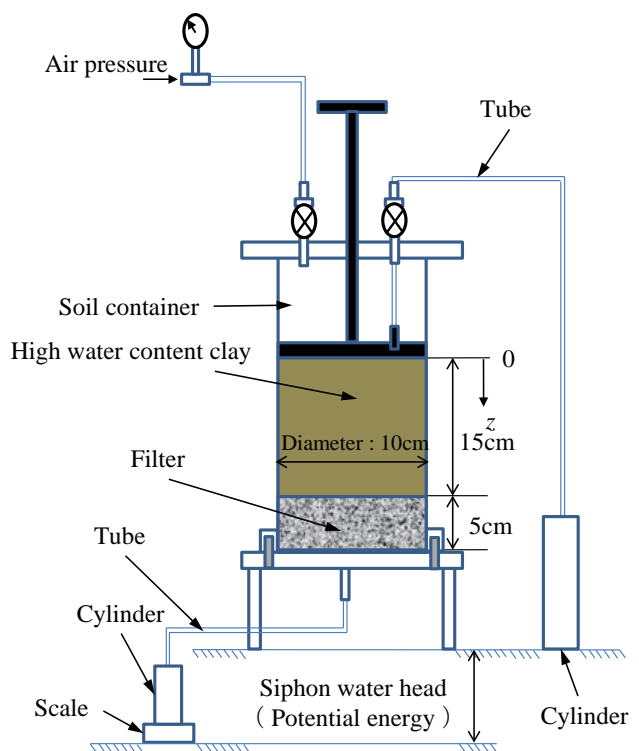

Fig.9. Consolidation test apparatus by siphon method and air pressure.

methods had little influence on water content tendency. The relationships between shear strength and depth are shown in Fig.7. The shear strength increased with an increase of depth, which is closer to the filter material.

The average of the shear strength which GBF-slag is used as the filter material became larger than that of Toyoura sand. It is considered that solidification progressed with time by eluting alkali ingredient to the dredged soil from GBF-slag filter material. It is necessary to analyze dredged soil near the border between dredged soil and the filter material chemically.

In order to confirm the drainage performance of porous filter material by using siphon method, same consolidation tests were performed under different test conditions using porous filter materials. Fig.8 shows the relationships between drainage amount and elapsed time using different filter materials by siphon method. As shown in this figure, consolidation drainage initially occurred and later converged to the constant values at least until $60 \mathrm{~min}$ in all the filter material conditions. Even if the filter material which was mixed with Toyoura sand and porous material (GBF-slag) was used as a filter material, similar tendency was also indicated. It was clarified from the laboratory tests that it is impossible to dewater the high water content dredged soil by using siphon method with unsaturated porous filter material such as zeolite or granular blast furnace slag continuously. In the case of using porous materials as filter, there is some possibility to be an unsaturated condition of filter. To establish the embankment construction system that possess the drainage and purification function by utilizing clean energy such as siphon method, it is important to keep the state of water inflow from dredged soil into the porous filter material. It is necessary to investigate the saturation of filter material and differences of hydraulic conductivity between dredged soil and filter materials. 


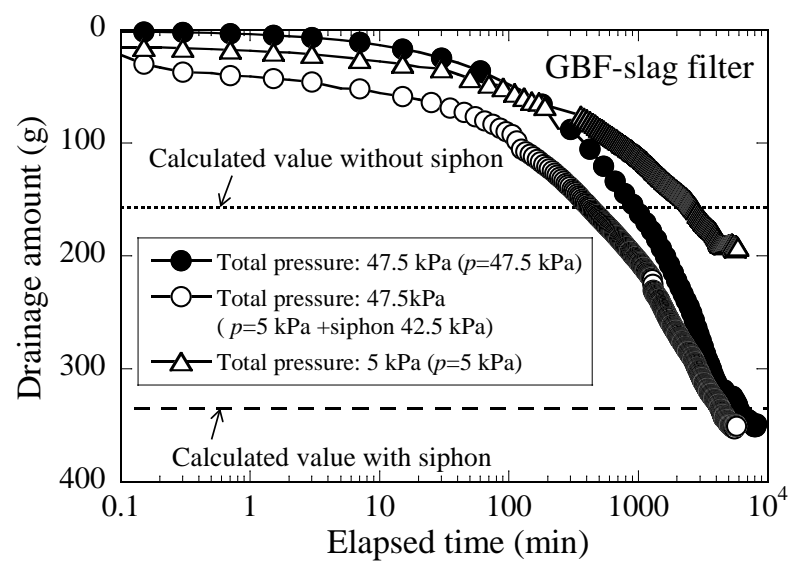

Fig.10. The relationships between drainage amount with time using siphon method and vertical pressure.

\section{CONSOLIDATION TEST BY SIPHON MESHOD AND AIR PRESSURE}

\subsection{Test method and procedure}

In order to investigate the proper use of porous filter materials, a small size consolidation test apparatus was prepared by using a new container of inner diameter $10 \mathrm{~cm}$ in Fig.9. Heights of the filter material and dredged soil and compaction procedure are unified with the former experiments. PBD was not set at the bottom of the filter material. Consolidation tests were performed under double drainage condition. GBF-slag was used as a filter material. Vertical pressure is applied on the upper part of dredged soil by air pressure. In this testing, $5 \mathrm{kPa}, 47.5 \mathrm{kPa}$ by vertical pressure and $5 \mathrm{kPa}$ by vertical pressure with siphon method (42.5 $\mathrm{kPa}$ ) were applied to the double layered specimens, respectively. Drainage amounts with elapsed time were measured.

\subsection{Test results and discussions}

Fig.10 shows the relationships between consolidation drainage amount and elapsed time. In both cases that only $5 \mathrm{kPa}$ of vertical pressure $p$ and $5 \mathrm{kPa}$ of vertical pressure $p$ with siphon method (42.5kPa), consolidations were performed through the filter. It is considered that inflow of water from the dredged soil to the porous filter material were occurred by applying the vertical pressure. From the test results, the consolidation drainage amount of $5 \mathrm{kPa}$ of vertical pressure with siphon method became larger than that of only $5 \mathrm{kPa}$ of vertical pressure with time. Furthermore, drainage amount and elapsed time relationship curve that vertical pressure of $47.5 \mathrm{kPa}$ is applied had different tendency in comparison with that of $5 \mathrm{kPa}$ of vertical pressure with siphon method. However, the final consolidation drainage amount of $5 \mathrm{kPa}$ of vertical pressure with siphon method reached to the almost same value of $47.5 \mathrm{kPa}$ of vertical pressure. By combining siphon method and vertical pressure, it was indicated the possibility to dewater the same amount of volume in the case of vertical pressure $p=47.5 \mathrm{kPa}$ due to the functional recovery of siphon method.

\section{CONCLUSION}

In this study, series of tests were conducted to investigate the dewatering behavior and strength properties of the dredged soil with vacuum and siphon methods by using different filter materials (Toyoura sand, zeolite, granular blast furnace slag), respectively. The main conclusions obtained from this study are as follows;

1) High water content dredged soil can be consolidated by using siphon method with saturated filter material such as Toyoura sand. The effectiveness for dewatering by siphon method is almost equal to that of vacuum consolidation method in the view point of reducing the volume and increasing the strength.

2) It is impossible to dewater the high water content dredged soil by using siphon method with unsaturated porous filter material such as zeolite or granular blast furnace slag continuously. However, by using siphon method with vertical pressure, there is some possibility to dewater the dredged soils.

\section{ACKNOWLEDGEMENTS}

This work was partly supported by Interdisciplinary program in education and projects in research development (P\&P) at Kyushu University. The authors express their thanks to Mr. M. Nakashima, who is a technical staff In addition the authors acknowledge to Prof. N. Yasufuku for his continuous academic advices.

\section{REFERENCES}

1) Kasama, K., Zen, K.,Chen, G. and Kuratomi K. (2007) : Strength property and pollutant elution characteristics of contaminated sediment treated by cement-mixing and mechanical dehydration, Journal of Japan Society of Civil Engineers Division C, Vol. 63, No.2, 544-552 (in Japanese).

2) Matuda, H., Ishikura, R., Wada, M., Kitayama, N., Baek, W. and Tani, N.(2012): Aging effect on the physical and mechanical properties of granulated blast furnace slag as lightweight banking, Japanese Geotechnical Journal,Vol.7, No.1, 339-349( in Japanese).

3) Tong, J., Yasufuku, N., Omine, K. and Kobayashi, T.(2010): Experimental study on the dewatering behavior of the dredged mud with horizontal drainage by siphon method, Geosynthetics Engineering Journal, Vol.25, 267-270.

4) Umezaki, T., Kawamura, T., Nishida, K., Ishii, D. and Sakai, D.(2011): Development of a fence for water quality purification using geosynthetics, Geosynthetics Engineering Journal, Vol.26, 175-182( in Japanese). 